maining 50\%). NordFood's research areas include food packaging, quality control, information technologies and data analysis, food hygiene, and new methods and processes. Its 30 projects involve independent collaboration by participants from all the Nordic countries.

NordList, the programme for lightweight structures (with $23 \%$ of the 1994 NIF grant budget), aims to make Nordic industry more competitive in sectors in which high levels of expertise already exist. This goal will be achieved by encouraging industry and leading research centres to collaborate in the development of design and production technologies and methods of material selection which are expected to play a key role in industrial applications related to lightweight structures within the next seven years. The entire lifecycle of products is being evaluated with respect to resource issues and the environment. The aspects involved include production of raw materials, production of products, use of products and recycling. The techniques that have been developed are now being adapted in a separate comprehensive project which was initiated in 1994.

Nordic Wood, for the wood industry, and NordPap, for the pulp and paper industry, together received $35 \%$ of the NIF grant budget in 1994. Nordic Wood aims to "... improve the competitiveness of Nordic wood relative to substitute materials like steel and plastics". Started in 1994, there are six priorities (wood and the environment; improving the properties of wood; wood as an engineering material; order and delivery precision; new markets and new products; and new production systems)

NordPap deals with new technology for the pulp and paper industry and has four sub-programmes (properties of virgin fibre and recycled fibre; modern bleaching technology; paper as an information-carrying medium; European standards). The participants once again come from all the Nordic countries and most of the companies active in the pulp and paper industry are involved. Research is mainly carried out in universities and in industrial research institutes. The total planned budgets are approximately 135 MNKR for Nordic Wood and 120 MNKR for NordPulp, with both having the usual breakdown of $50 \%$ industry $/ 30 \%$ $\mathrm{NIF} / 20 \%$ national.

\section{Other Initiatives}

Several other R\&D institutions and programmes exist under the auspices of the Nordic Council of Ministers, but two deserve special mention in the context of Nordic industrial research. The Nordic Investment Bank (NIB) was established 1976 by the five Nordic countries to attract international capital to the Nordic area. It offers, on normal commercial conditions, financial loans and guarantees to investment projects involving at least two Nordic countries. Second, there is a close academic cooperation between Nordic universities that includes exchange and training programmes for graduate students and research staff. Academic cooperation sometimes take place on network basis but is usually organized by institutions such as the Nordic Research Academy, the Nordic Research Council's Cooperation Committee, the Nordic Rectors Conference, etc. A continuation of the very successful Nordic Industrial Ph.D. Programme is currently under consideration. Strengthening collaboration with industry in western Europe has been one of NIF's aims. This will assume increasing importance as the Fund moves it focus from primarily Nordic cooperation following the decision of some countries to join the European Union.

\title{
SCIENTIFIC COOPERATION WITH THE THIRD WORLD
}

\section{Lennart Hasselgren}

Director, International Program in the Physical Sciences, Uppsala

The International Program in the Physical Sciences (IPPS) was created in 1961 as the International Seminar in Physics (the name changed to the present one in 1987). Based at Uppsala University, as a special unit belonging to the Faculty of Science and Technology, it focuses on establishing viable research teams in selected developing countries in Latin America, Africa and Asia. There are at present about 30 projects in research areas which should be chosen by the countries themselves and involve physics or related fields.

The IPPS does not represent the only support given by Nordic countries to physics in developing countries. For example, the Norwegian universities' Committee for Development, Research and Education, funds activities in Botswana, Uganda and Tanzania and there are projects directly supported by the Swedish Agency for Research Cooperation with Developing Countries (SAREC); additional support is also found within general aid programmes. However, the IPPS as an organization plays a unique role since it is based on establishing longterm links with advanced research teams. The IPPS is therefore not oriented towards individuals, and the long-term goals often entail cooperation for 10 years or more.

Links at the research level are the core element of the IPPS. They essentially involve North-South cooperation with research groups based mainly in the Nordic countries, and South-South cooperation where we identify regional advanced groups to serve as hosts.
As the IPPS is mainly concerned with countries where physics and related fields are very weak one is talking about capacity building, with most of the IPPS projects in universities. Consequently, within the projects supported the IPPS assists in developing M.Sc. and Ph.D. programmes based on the sandwich model where as much of the work as possible is done at the home institute, with a supervisor from the host institute. Whenever possible, degrees should be awarded by the home institute. Most African universities with whom we co-operate in fact seek such an arrangement to ensure good quality theses. But this need is often the same in regions that may be looked upon as being relatively strong. Thus, the first $\mathrm{Ph} . \mathrm{Ds}$ to graduate in physics in Peru and Ecuador came from sandwich programmes sponsored by IPPS.

\section{A Nordic Approach is Natural}

The IPPS's use of research capacity in all the Nordic countries is not organized formally by a government body such as the Nordic Council. It developed instead at the beginning of the 1980s in a natural and informal way since physicists in the Nordic countries are used to cooperation, and because the Nordic countries have rather similar views regarding aid to developing countries. There is, for example, a general willingness to support the long-term development of scientific infrastructure.

Several practical considerations perhaps explain why this Nordic cooperation deve-
L. Hasselgren, third from the left, stepped down in March 1995 as the Chairman of the EPS Interdivisional Group of Physics for Development (IGPD). He is seen here with (from the left) $P$. Brault, the IGPD Secretary, A. Suzor Weiner, who chairs the Group and J.J. Steyaert, the Vice-Chair.

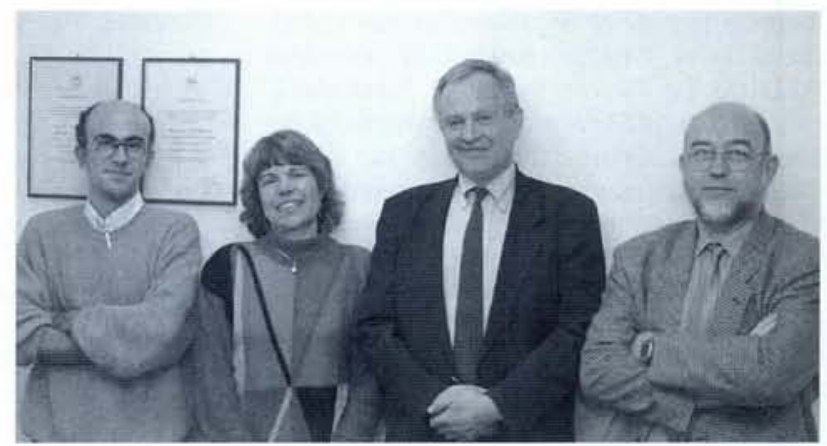


loped. Nordic countries are small so to be able to respond to requests for support we must have a broad base. Secondly, there is a limited number of research groups with activities suitable for developing countries. Thirdly, it is advantageous from the administrative and coordinating points of view to have a single sponsoring organization. Good background information is essential and the IPPS has been able to gather it since 1961: building up a similar capacity in each of the Nordic countries would expensive and inefficient. Finally, while there are several organizations which deal with direct support of physics in the third world, coordination at the Nordic level is important to use efficiently the limited funds which are available.

The involvement of research teams from more than one Nordic country has resulted in increased funding. The IPPS is mainly financed by the Swedish government through SAREC. There is also additional support from Uppsala University and UNESCO, and since 1989 from Norway's Ministry of Foreign Affairs. The last source contributes today roughly $20 \%$ of our budget (10.5 MSKR in $1994 / 5$, equivalent to about $1 \mathrm{MECU}$ ) and since only a small part is for administration, the Norwegian funds are essential for providing a satisfactory level of direct input.

\section{A Nordic Organization is Vital}

One may ask why there is a need for an organization like the IPPS, and why it should be linked to a university. First of all, the most advantageous initiatives try to build up direct cooperation, and to do this as closely as possible with those involved. Thus, one should strive at creating as direct as possible contacts between scientists. There are of course many activities aimed at strengthening physics in developing countries which stem from individual initiatives by scientists; they should be neither neglected nor underrated for they automatically have this "scientist-scientist" contact built in. But the need for support to the third world is so large and so varied that there should be an organization behind it.

Moreover, it is natural for a scientist involved in, for example, tropical medicine or natural products to establish contacts with research groups in developing countries.

A CATALOGUE ON
RESEARCH ACTIVITIES IN PHYSICS AND
RELATED FIELDS IN EASTERN AND
SOUTHERN AFRICA

Published in March 1994 (100 pages) by the International Program in the Physical Sciences Authors: L. Hasselgren \& R. Kivaisi

\section{HIGHLIGHTS}

- Most physics-related research in East and South Africa is carried out in universities.

- The most active fields are: geosciences, applications, nuclear physics, renewable energy. - Ranking for publications in international journals by individual scientists: Kenya (average of 5 publications p.a. for 1987-1992), Botswana, Sudan.

Available in limited numbers free-of-charge from: IPPS, ISP, Uppsala Univ., Dag Hammarskjölds vag 31, S-752 37 Uppsala.

\section{FURTHER INFORMATION}

\section{- NORDITA and Nordic physics centres:}

Director: P. Hoyer, NORDITA, Blegdamsvej, DK-2100 Copenhagen $\varnothing$ (tel.: +45-35 3252 22; fax: +45-33 9235 01). WWW home page: http://www.nordita.dk/ (accessible through EurophysNet at http://www.nikhef. $\mathrm{nl} / \mathrm{www} / \mathrm{pub} / \mathrm{eps} /$, the European physical societies network cordinated by EPS).

- Nordic Industrial Fund, Nedre Vollgate 8, N-0158 Oslo. Executive Director: O. Poulsen, Forskningsministeriet, Bredgade 43 , DK-1260 Copenhagen K (tel.: +45-33 9297 00). Publication: New Nordic Technology (4 issues p.a.).

- International Program in the Physical Sciences (IPPS): Director, ISPP, ISP, Uppsala Univ., Dag Hammarskjölds väg 31, S-752 37 Uppsala (tel.: +46-18-18 35 76; fax: $+46-18-183495)$.

But a physicist does not have the same incentives so physics requires an appropriate organization to initiate, support and help plan long-term cooperation. To be effective, training and contacts must be followed up by direct inputs to the developing countries. These inputs take many different forms and must be tailor-made for each project. Our experience shows that if an organization such as the IPPS backs a project by taking care of practical matters, leaving the scientific questions to the research groups, then it is not difficult to find groups willing to establish collaborations. Having said this, the cooperation must of course be carried out as much as possible according to the conditions requested by the developing country.

This need for an organization is also reinforced if one considers the building up of research capacity in a weak research environment. Long-term commitments are essential to have any success in creating a base. In cases where we start from scratch, there will be many questions which are difficult to solve on an individual basis even if some funding is available. Hence I believe that support of the type offered by the European Union (EU) which is based upon cooperation between at least two European laboratories and one laboratory in the third world for a limited time is inappropriate in such cases. We see that whenever groups supported by us have been selected for EU funding, they were without exception groups that had already reached a certain level of maturity.

\section{South-South Cooperation}

I have so far mainly talked about NorthSouth cooperation as a basis for support to physics in the developing world. However, maybe even more important is the ability to make use of the region's more advanced research groups. This South-South cooperation is built up within the IPPS in the same way as the North-South cooperation by using for instance so-called resource groups in Argentina, Brazil and Mexico and in parts of Asia. It is rewarding to see that some African groups can also serve as resource groups. For instance, an IPPS-supported group working on materials for solar-energy conversion in Dar es Salaam, Tanzania, has developed so positively that it now takes in $\mathrm{MSc}$ and $\mathrm{PhD}$ students from neighbouring countries. It also organizes IPPS-sponsored biannual workshops/colleges for young physicists from the region. The 1988 workshop organized in Nairobi, Kenya, by the EPS Interdivisional Group for Physics for Development on Planning of Network Projects in Materials Science and Solar Energy showed that such events can have a very significant impact.

The IPSS experience in Nordic cooperation is entirely positive so we would hope to be able to develop further our activities. The response by Nordic physicists is also positive and many research groups are interested in cooperating with the developing world. The IPPS can use its existing organization to channel more funds. As the need is enormous, we naturally hope that they will be made available, and that future funding will not be affected by the recent decisions in Sweden, Norway and Finland to restructure organizations handling aid to the third world (in the case of Sweden, SAREC will disappear as an autonomous body and support of science in developing countries will come under a single department within a new organization).

Membership of the European Union implies additional sources of funding, but like many "newcomers" we have not yet been able to obtain a complete picture of all the new possibilities. The EU programme Amérique Latine - Formation Académique (ALFA) represents an interesting approach for developing networks. Networking is also important for research so it will be interesting to see if ALFA funds could be made available for physics-related research activities. One should of course encourage research teams to seek EU funding for cooperation projects. However, as was already mentioned, I do not view some of the EU programmes known to me as providing the solution for countries most needing support. Other measures are required in these cases.

Finally, the IPPS seeks closer cooperation with other organizations dealing with the support of physics in developing countries such as the International Centre for Theoretical Physics, the Third-World Academy of Sciences and the International Atomic Energy Agency. This is because the efficient use of the limited funds available for developing physics in the third-world clearly calls for more coordination.

ECASIA'95
6th European Conference on
APPLICATIONS OF
SURFACE \& INTERFACE ANALYSIS
Montreux, Switzerland
9-13 OCTOBER 1995
For the submission of abstracts and for infor-
mation on Short Courses and the Conference
Exhibition, please contact the Conference Se-
cretary: Dr. C. Hollenstein, ECASIA'95, EPFL-
DMX, CH-1015 Lausanne.
Tel. +41-21-693 3471 - Fax +41-21-693 3946
E-mail: mathieu@ Imch.dmx.epfl.ch
Deadline for reduced registration fee: 25 July 1995

